\title{
Electronic structures and electron-injection mechanisms of cesium-carbonate-incorporated cathode structures for organic light-emitting devices
}

\author{
Chih-I Wu, ${ }^{\text {a) }}$ Chan-Tin Lin, Yu-Hung Chen, and Mei-Hsin Chen \\ Department of Electrical Engineering, and Graduate Institute of Electro-Optical Engineering, \\ National Taiwan University, Taipei, Taiwan 10617, Republic of China \\ Yin-Jui Lu and Chung-Chih Wu \\ Department of Electrical Engineering, National Taiwan University, Taipei, Taiwan 10617, Republic \\ of China; Graduate Institute of Electro-Optical Engineering, National Taiwan University, Taipei, Taiwan \\ 10617, Republic of China; and Graduate Institute of Electronics Engineering, \\ National Taiwan University, Taipei, Taiwan 10617, Republic of China
}

(Received 5 December 2005; accepted 22 February 2006; published online 10 April 2006)

\begin{abstract}
In this letter, we investigate electronic structures and electron-injection mechanisms of the effective cathode structures for organic light-emitting devices incorporating cesium carbonate $\left(\mathrm{Cs}_{2} \mathrm{CO}_{3}\right)$, either deposited as an individual thin injection layer or doped into the organic electron-transport layers. The electronic structures and the interface chemistry studied by ultraviolet and x-ray photoemission spectroscopy show that the enhanced electron injection is associated with strong $n$-doping effects and increase of electron concentrations in the electron-transport layer induced by $\mathrm{Cs}_{2} \mathrm{CO}_{3}$. Since such a reaction occurs without the presence of metals, cathode structures incorporating $\mathrm{Cs}_{2} \mathrm{CO}_{3}$ may be applied to a wide range of electrode materials. (C) 2006 American Institute of Physics. [DOI: 10.1063/1.2192982]
\end{abstract}

An effective cathode structure for efficient electron injection is critical to performances of organic light-emitting devices (OLEDs). An efficient electron injection could be achieved by using low-work-function metals, either as individual cathode layers or as $n$-type conductive dopants in the organic electron-transport layers (ETLs). ${ }^{1-6}$ These methods, however, require special care and equipments for handling reactive metals and thus are less convenient for fabrication. Another commonly used cathode structure that involves no reactive metals is to insert an ultrathin layer of alkali halide, such as LiF, as an electron-injection layer (EIL) between a metal cathode and an organic ETL. Since such a scheme usually involves particular chemical interaction of metal/ EIL/ETL, its effectiveness is sensitive to the metal used and very often limits the choice of cathode metals to $\mathrm{Al}$ only. Recently, Cannon Inc. reported that cesium carbonate $\left(\mathrm{Cs}_{2} \mathrm{CO}_{3}\right)$, either vacuum deposited as an individual layer over the organic ETL or codeposited with ETL, effectively facilitates electron injection from a wide range of metal electrodes. ${ }^{7}$ While device performances using such cathode structures are encouraging, mechanisms of this injection scheme are not understood. In this letter we investigate the electronic structures and electron-injection mechanisms of cathode structures incorporating $\mathrm{Cs}_{2} \mathrm{CO}_{3}$ using photoemission spectroscopy. Furthermore, since Cannon Inc. did not disclose the ETL used in their report, in this work we also test whether such an injection scheme is also effective with other widely used ETLs such as tris(8hydroxyquinolate)aluminum $\left(\mathrm{Alq}_{3}\right){ }^{8}$

The effects of $\mathrm{Cs}_{2} \mathrm{CO}_{3}$ on electron injection from metal cathodes into $\mathrm{Alq}_{3}$ were investigated via a series of devices structures: (1) devices using no electro-injection layer [ITO/

\footnotetext{
${ }^{a}$ Author to whom correspondence should be addressed; electronic mail:
} chihiwu@cc.ee.ntu.edu.tw
PEDT:PSS $(20 \mathrm{~nm}) / \alpha$-NPD $(40 \mathrm{~nm}) / \mathrm{Alq}_{3}(60 \mathrm{~nm}) / \mathrm{Al}($ device A) or $\mathrm{Ag}$ (device $\mathrm{B})$, (2) devices using a thin layer of $\mathrm{Cs}_{2} \mathrm{CO}_{3}$ as the electron-injection layer [ITO/PEDT:PSS $(20 \mathrm{~nm}) / \alpha$-NPD $(40 \mathrm{~nm}) / \mathrm{Alq}_{3}(60 \mathrm{~nm}) / \mathrm{Cs}_{2} \mathrm{CO}_{3}(1 \mathrm{~nm}) / \mathrm{Al}$ (device C) or $\mathrm{Ag}$ (device D)], (3) devices using $\mathrm{Alq}_{3}$ doped with 20 wt $\%$ of $\mathrm{Cs}_{2} \mathrm{CO}_{3}$ as the electron-injection layer [ITO/PEDT:PSS $(20 \mathrm{~nm}) / \alpha$-NPD $(40 \mathrm{~nm}) / \mathrm{Alq}_{3}(40 \mathrm{~nm}) /$ $\mathrm{Alq}_{3}: \mathrm{Cs}_{2} \mathrm{CO}_{3}(20 \mathrm{~nm}) / \mathrm{Al}$ (device E) or Ag (device F)], and (4) a "benchmark" device (device G) using $\mathrm{LiF}$ as the electron-injection layer [ITO/PEDT:PSS $(20 \mathrm{~nm}) / \alpha$-NPD $\left.(40 \mathrm{~nm}) / \mathrm{Alq}_{3}(60 \mathrm{~nm}) / \mathrm{LiF}(0.5 \mathrm{~nm}) / \mathrm{Al}\right]$. In these devices, the conducting polymer poly(ethylene dioxythiophene)/ poly(styrene sulphonate) (PEDT:PSS) and 4,4'-bis[ $N$-(1-naphyl)- $N$-phenyl-amino]biphenyl ( $\alpha$-NPD) are used as the hole-injection and hole-transport layers, respectively. ${ }^{9,10}$ PEDT:PSS was prepared by spin coating and all other layers were vacuum deposited in sequence without breaking the vacuum.

Photoemission experiments were carried out in two interconnected ultrahigh-vacuum chambers, one for deposition and one for spectroscopy analysis. ${ }^{11}$ Thin films of $\mathrm{Alq}_{3}$ were prepared in the deposition chamber by thermal evaporation onto gold-coated silicon substrates. $\mathrm{Cs}_{2} \mathrm{CO}_{3}$ were deposited on $\mathrm{Alq}_{3}$ thin films or coevaporated with $\mathrm{Alq}_{3}$. The core-level $\mathrm{x}$-ray photoemission spectra (XPS) were measured using either $\mathrm{Al} K \alpha(1486.6 \mathrm{eV})$ or $\mathrm{Mg} K \alpha(1253.6 \mathrm{eV})$ photon lines. The valence-band ultraviolet photoemission spectra (UPS) were carried out with He I $(21.2 \mathrm{eV})$ and $\mathrm{He}$ II $(40.8 \mathrm{eV})$ as excitation sources. The Fermi level of the system was measured on the gold substrate before the organic deposition. The energy levels of the highest occupied molecular orbitals (HOMOs) of organic samples were determined by extrapolating the edges of the HOMO peak down to the background of the UPS spectra. The overall resolutions for XPS and UPS are 0.5 and $0.15 \mathrm{eV}$, respectively, in our system. 


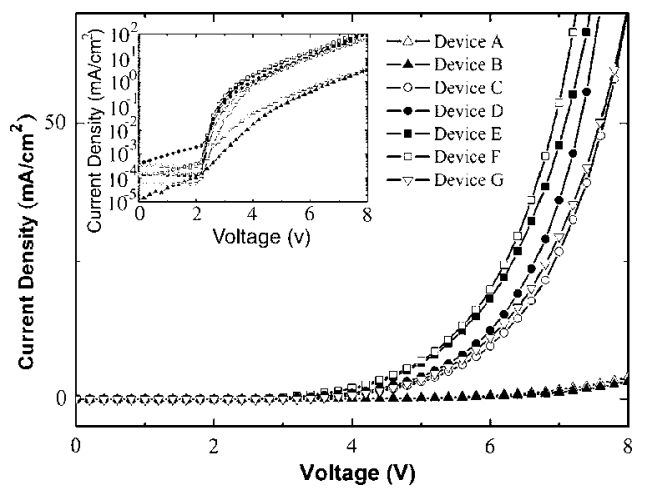

FIG. 1. I-V characteristics of devices A-G.

The current-voltage $(I-V)$ characteristics of devices A-G are shown in Fig. 1. Without an appropriate injection scheme, devices A and B show poor $I-V$ characteristics. With a thin layer of $\mathrm{Cs}_{2} \mathrm{CO}_{3}$ inserted between $\mathrm{Alq}_{3}$ and cathode metals (devices $\mathrm{C}$ and $\mathrm{D}$ ) the currents are increased by over two orders of magnitude, comparable to or even higher than that obtained with the LiF/Al cathode structure (i.e., the benchmark scheme, device G). Moreover, $I-V$ characteristics are further improved with coevaporation of $\mathrm{Cs}_{2} \mathrm{CO}_{3}$ and $\mathrm{Alq}_{3}$ as part of the ETL (i.e., devices E and F). It is interesting to note that in contrast to $\mathrm{LiF}$, which only works effectively with $\mathrm{Al}, \mathrm{Cs}_{2} \mathrm{CO}_{3}$ is effective for both $\mathrm{Al}$ and $\mathrm{Ag}$ cathodes. Previous studies have shown that the formation of an effective cathode with $\mathrm{LiF} / \mathrm{Al}$ is due to the release of $\mathrm{Li}$ ions from $\mathrm{LiF}$ into the $\mathrm{Alq}_{3}$ matrix and consequent formation of $\mathrm{Al}_{3}{ }^{-}$ anion through the chemical reaction between $\mathrm{LiF}$ and $\mathrm{Al}{ }^{11-14}$ Such reactions require the presence of $\mathrm{Al}$ and may not occur with other metals. Here, the fact that $\mathrm{Cs}_{2} \mathrm{CO}_{3}$ also works effectively for metals other than $\mathrm{Al}$ implies different reaction mechanisms. To understand the mechanisms, we thus further studied the interfacial chemistry and energy levels in these cathode structures with photoemission spectroscopy.

Figure 2 shows the UPS spectra near the onset and the valence bands with incremental $\mathrm{Cs}_{2} \mathrm{CO}_{3}$ deposition on $\mathrm{Alq}_{3}$, which allows us to investigate energy structures and chemical reactions at the interfaces. The nominal thickness is obtained from the quartz oscillator calibrated with densities and geometric factors. $1 \AA$ of $\mathrm{Cs}_{2} \mathrm{CO}_{3}$ is equivalent to $2.5 \times 10^{14} \mathrm{~cm}^{-2}$ molecules on the surface. For pristine $\mathrm{Alq}_{3}$, the edge of HOMO is about $1.5 \mathrm{eV}$ below the Fermi level
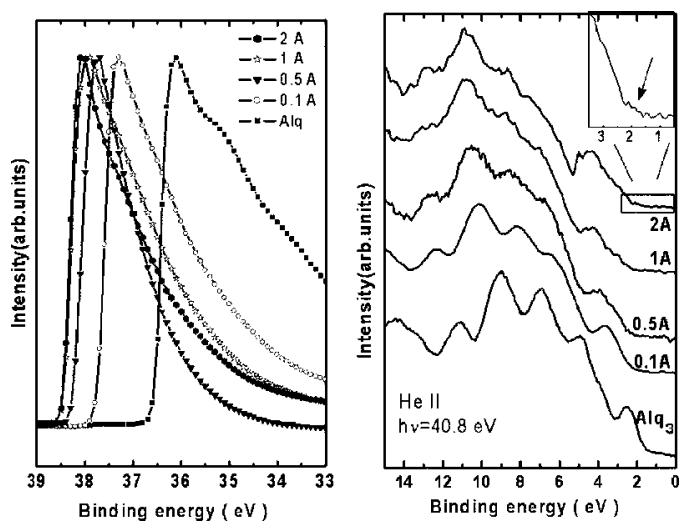

FIG. 2. The UPS spectra near the onset and valence bands as a function of incremental deposition of $\mathrm{Cs}_{2} \mathrm{CO}_{3}$ on $\mathrm{Alq}_{3}$. The surface state is indicated by the arrow in the inset.
Downloaded 17 Feb 2009 to 140.112 .113 .225 . Redistribution subject to AlP ${ }_{3} \mathrm{Cs}_{2} \mathrm{CO}_{3}$ of $64: 1$ and $16: 1$ weight ratios). As in the case
FIG. 3. Evolution of energy band diagrams, from left to right, with incremental deposition of $\mathrm{Cs}_{2} \mathrm{CO}_{3}$ on $\mathrm{Alq}_{3}$.

and the ionization energy is $5.8 \mathrm{eV}$, which is consistent with the reported data. ${ }^{15-18}$ With as little as $0.1 \AA \mathrm{Cs}_{2} \mathrm{CO}_{3}$ deposited on the $\mathrm{Alq}_{3}$ surfaces, the onset of UPS spectra, which represents the vacuum level of the sample, is lowered by $1.2 \mathrm{eV}$. The abrupt lowering of the vacuum levels indicates charge exchanges and a strong dipole field at the interfaces with $\mathrm{Cs}_{2} \mathrm{CO}_{3} \cdot{ }^{19,20}$ The valence-band features of the $\mathrm{Alq}_{3}$ are still clearly seen in the UPS spectrum, yet with HOMO and other peaks rigidly shifting toward lower binding energies by $1.1 \mathrm{eV}$ with respect to the Fermi level. Given the band gap of $\mathrm{Alq}_{3}$ being $2.8 \mathrm{eV}$, the Fermi level is only $0.2 \mathrm{eV}$ below the lowest unoccupied molecular orbital (LUMO) (Fig. 3), indicating that the $\mathrm{Alq}_{3}$ film becomes $n$ doped with $\mathrm{Cs}_{2} \mathrm{CO}_{3}$ deposition. The influence of $\mathrm{Cs}_{2} \mathrm{CO}_{3}$ on electronic structures of $\mathrm{Alq}_{3}$ is quite different from that of $\mathrm{LiF}$. In the $\mathrm{Alq}_{3} / \mathrm{LiF} / \mathrm{Al}$ cathode structure, the $n$-doping effect of $\mathrm{Alq}_{3}$ only occurs with the subsequent deposition of $\mathrm{Al}$, which reacts with $\mathrm{LiF}$ and forms $\mathrm{AlF}_{3}{ }^{11-14}$ The $\mathrm{Li}$ atoms are then released into the $\mathrm{Alq}_{3}$ matrix and generate Lication and $\mathrm{Al}_{3}{ }^{-}$anion, resulting in $n$-doped $\mathrm{Alq}_{3}$. In contrast, the photoemission results here show that $0.1 \AA \mathrm{Cs}_{2} \mathrm{CO}_{3}$ alone (without subsequent metal deposition) can induce strong $n$-doping effects in $\mathrm{Alq}_{3}$. Such characteristics would render this scheme rather insensitive to cathode metals, as already observed in the device results. With increasing $\mathrm{Cs}_{2} \mathrm{CO}_{3}$ coverage, the $\mathrm{HOMO}$ of $\mathrm{Alq}_{3}$ shifts further toward the lower binding energy, along with a similar shift of the vacuum level. Some surface states are also observed at the top of HOMO after $2 \AA$ of $\mathrm{Cs}_{2} \mathrm{CO}_{3}$ depositions. Furthermore, the energy level of $\mathrm{Alq}_{3} \mathrm{HOMO}$ is more than $2.8 \mathrm{eV}$ below the Fermi level with $\mathrm{Cs}_{2} \mathrm{CO}_{3}$ coverage larger than $0.5 \AA$, suggesting heavily $n$-doped $\mathrm{Alq}_{3}$ surfaces. The Fermi level being more than $2.8 \mathrm{eV}$ (optical absorption band gap) above the $\mathrm{HOMO}$ of $\mathrm{Alq}_{3}$ may be due to the fact that photoemission data involve the molecular anion-cation gap, which is typically $0.5-1.5 \mathrm{eV}$ larger than the optical gap of neutral molecules. ${ }^{21,22}$ Therefore, the Fermi level could still be below the LUMO of $\mathrm{Alq}_{3}$ in this case. The energy-level diagrams of $\mathrm{Alq}_{3}$ with incremental deposition of $\mathrm{Cs}_{2} \mathrm{CO}_{3}$ are summarized in Fig. 3, illustrating that the Fermi level at the interface can move close to, or even above, LUMO with a thin layer of $\mathrm{Cs}_{2} \mathrm{CO}_{3}$. As a result, the electron-injection barrier, i.e., the energy difference between the Fermi level of the electrode and the LUMO at the interface, is greatly reduced.

Figure 4 shows the UPS spectra of pristine $\mathrm{Alq}_{3}$ and $\mathrm{Alq}_{3}$ doped with two different $\mathrm{Cs}_{2} \mathrm{CO}_{3}$ concentrations $\left(\mathrm{Alq}_{3}: \mathrm{Cs}_{2} \mathrm{CO}_{3}\right.$ of $64: 1$ and 16:1 weight ratios). As in the case to AlP license or copyright; see http://apl.aip.org/apl/copyright.jsp 

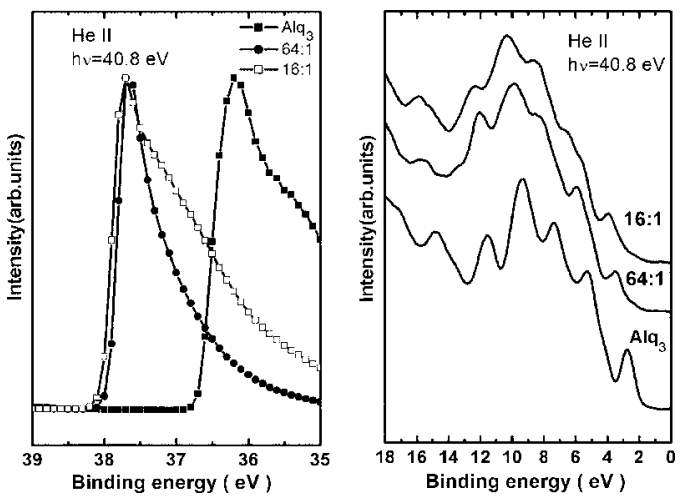

FIG. 4. The UPS spectra near the onset and valence bands for pristine $\mathrm{Alq}_{3}$ and $\mathrm{Alq}_{3}$ doped with two $\mathrm{Cs}_{2} \mathrm{CO}_{3}$ concentrations $\left(\mathrm{Alq}_{3}: \mathrm{Cs}_{2} \mathrm{CO}_{3}\right.$ of $64: 1$ and 16:1 weight ratios).

of thin $\mathrm{Cs}_{2} \mathrm{CO}_{3}$ on $\mathrm{Alq}_{3}$, with $\mathrm{Cs}_{2} \mathrm{CO}_{3}$ doping the valenceband features of $\mathrm{Alq}_{3}$ can still be clearly distinguished, and yet shift rigidly to higher binding energies as compared to that of pristine $\mathrm{Alq}_{3}$. There also occur extra states at the top of the $\mathrm{Alq}_{3} \mathrm{HOMO}$ with the presence of $\mathrm{Cs}_{2} \mathrm{CO}_{3}$ in the matrix. These extra states in the forbidden gap might provide a ladder for carrier injection across the interfacial regions. With $\mathrm{Cs}_{2} \mathrm{CO}_{3}$ doping, the energies of $\mathrm{Alq}_{3} \mathrm{HOMO}$ are lowered by 0.9 and $1.3 \mathrm{eV}$ for the mixing ratios of $1 / 64$ and $1 / 16$, respectively. With even higher concentrations, the Fermi levels saturate at the vicinity of the $\mathrm{Alq}_{3}$ LUMO level. In comparing the Fermi levels of samples with $\mathrm{Cs}_{2} \mathrm{CO}_{3}$ inserted at the interfaces or doped in the $\mathrm{Alq}_{3}$ matrix, it is found that the electron-injection barriers are similar and negligibly small for both cases. Lower device voltages observed for devices $\mathrm{E}$ and $\mathrm{F}$, with $\mathrm{Cs}_{2} \mathrm{CO}_{3}$ doped in $\mathrm{Alq}_{3}$, thus may be associated with enhanced conduction due to increased carrier concentrations. Therefore, doping $\mathrm{Cs}_{2} \mathrm{CO}_{3}$ in the $\mathrm{Alq}_{3}$ matrix not only reduces the electron-injection barrier but also increases the carrier concentration for current conduction.

The chemistry of $\mathrm{Cs}_{2} \mathrm{CO}_{3}$ and $\mathrm{Alq}_{3}$ was further investigated with XPS. First, a sample with $\mathrm{Cs}_{2} \mathrm{CO}_{3}$ deposited on the $\mathrm{Au}$ substrate is measured with XPS and the core-level intensities of $\mathrm{Cs}, \mathrm{C}$, and $\mathrm{O}$ verify that $\mathrm{Cs}_{2} \mathrm{CO}_{3}$ does not decompose during the evaporation. Thereby, all the characteristics observed in devices or in photoemission spectroscopy are results of interaction between $\mathrm{Cs}_{2} \mathrm{CO}_{3}$ and $\mathrm{Alq}_{3}$, not from other species, for instance, Cs decomposed from $\mathrm{Cs}_{2} \mathrm{CO}_{3}$. Figure 5 shows the XPS Cs $3 d$ core-level spectra of $\mathrm{Cs}_{2} \mathrm{CO}_{3}$ deposited on $\mathrm{Au}$ and $\mathrm{Alq}_{3}$ as well as $\mathrm{Cs}_{2} \mathrm{CO}_{3}$ codeposited with $\mathrm{Alq}_{3}$. The Cs $3 d_{3 / 2}$ and $3 d_{5 / 2}$ peaks of $\mathrm{Cs}_{2} \mathrm{CO}_{3}$ on $\mathrm{Au}$ appear at binding energies of 741.2 and $727.3 \mathrm{eV}$, respectively. For $\mathrm{Cs}_{2} \mathrm{CO}_{3}$ doped in $\mathrm{Alq}_{3}$ and $\mathrm{Cs}_{2} \mathrm{CO}_{3}$ deposited on $\mathrm{Alq}_{3}$, the Cs $3 d$ peaks both shift to higher binding energy by about $2 \mathrm{eV}$. The large difference in binding energies of Cs $3 d$ core levels in these samples indicates a substantial chemical reaction between $\mathrm{Cs}_{2} \mathrm{CO}_{3}$ and $\mathrm{Alq}_{3}$. The higher binding energies of the $\mathrm{Cs} 3 d$ core levels in the samples with $\mathrm{Alq}_{3}$ indicate additional positive charges surrounding the Cs atoms and a portion of the electrons being transferred to the host materials $\left(\mathrm{Alq}_{3}\right)$. The increase of the electron concentration in the $\mathrm{Alq}_{3}$ matrix would move the Fermi level close to LUMO of $\mathrm{Alq}_{3}$, consistent with the UPS results. Overall, both XPS and UPS show that the reactions between $\mathrm{Cs}_{2} \mathrm{CO}_{3}$ and $\mathrm{Alq}_{3}$ occur without presence of cathode metals. Thus the enhancement of electron injection brought by $\mathrm{Cs}_{2} \mathrm{CO}_{3}$ is

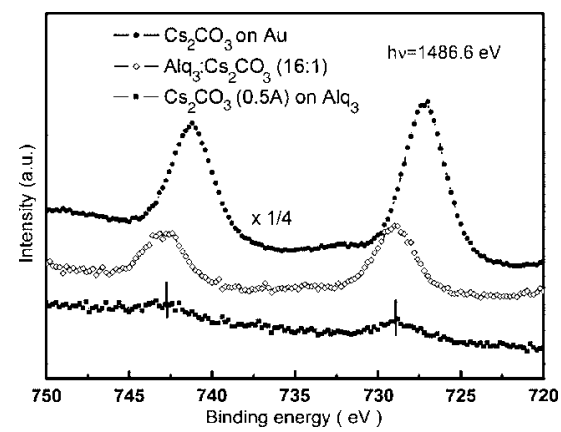

FIG. 5. The XPS spectra associated with $\mathrm{Cs} 3 d$ core levels of $\mathrm{Cs}_{2} \mathrm{CO}_{3}$ on $\mathrm{Au}$ and $\mathrm{Alq}_{3}$ and $\mathrm{Cs}_{2} \mathrm{CO}_{3}$ doped in $\mathrm{Alq}_{3}$ matrix.

rather independent of the cathode metals used, substantially different from mechanisms of the conventional $\mathrm{Alq}_{3} / \mathrm{LiF} / \mathrm{Al}$ cathode.

In summary, we investigate the electronic structures and mechanisms of the effective cathode structures incorporating $\mathrm{Cs}_{2} \mathrm{CO}_{3}$ either as an individual thin layer or doped into the organic electron-transport layer. The electronic structures and the interface chemistry studied by photoemission spectroscopy show that the enhanced electron injection is associated with $n$-doping effects and increase of electron concentrations. Since such a reaction occurs without the presence of metals, cathode structures incorporating $\mathrm{Cs}_{2} \mathrm{CO}_{3}$ may be applied to a wide range of electrode materials.

This work is supported by National Science Councils (NSC94-2112-M-002-017).

${ }^{1}$ Y. Gao and L. Yan, Chem. Phys. Lett. 380, 451 (2003).

${ }^{2}$ T. Schwieger, M. Knupfer, W. Gao, and A. Kahn, Appl. Phys. Lett. 83, 500 (2003).

${ }^{3}$ M. Pfeiffer, K. Leo, X. Zhou, J. S. Huang, M. Hofmann, A. Werner, and J. Blochwitz-Nimoth, Org. Electron. 4, 89 (2003).

${ }^{4}$ A. G. Werner, F. Li, K. Harada, M. Pfeiffer, T. Fritz, and K. Leo, Appl. Phys. Lett. 82, 4495 (2003).

${ }^{5}$ M. Y. Chan, S. L. Lai, C. S. Lee, and S. T. Lee, Chem. Phys. Lett. 380, 298 (2003).

${ }^{6}$ H. Ding and Y. Gao, Appl. Phys. Lett. 86, 213508 (2005).

${ }^{7}$ T. Hasegawa, S. Miura, T. Moriyama, T. Kimura, I. Takaya, Y. Osato, and H. Mizutani, SID Int. Symp. Digest Tech. Papers 35, 154 (2004).

${ }^{8}$ L. S. Hung, C. W. Tang, and M. G. Mason, Appl. Phys. Lett. 70, 152 (1997)

${ }^{9}$ J. Shi and C. W. Tang, Appl. Phys. Lett. 70, 1665 (1997)

${ }^{10}$ A. Elschner, F. Bruder, H. W. Heuer, F. Jonas, A. Karbach, S. Kirchmeyer, S. Thurm, and R. Wehrmann, Synth. Met. 111-112, 139 (2000).

${ }^{11}$ C. I. Wu, G. R. Lee, and T. W. Pi, Appl. Phys. Lett. 87, 212108 (2005).

${ }^{12}$ L. S. Hung, R. Q. Zhang, P. He, and G. Mason, J. Phys. D 35, 103 (2002)

${ }^{13}$ M. G. Mason, C. W. Tang, L. S. Hung, P. Raychaudhuri, J. Madathil, L. Yan, Q. T. Le, Y. Gao, S.-T. Lee, L. S. Liao, L. F. Cheng, W. R. Salaneck, D. A. dos Santos, and J. L. Brédas, J. Appl. Phys. 89, 2756 (2001).

${ }^{14}$ Q. T. Le, L. Yan, Y. Gao, M. G. Mason, D. J. Giesen, and C. W. Tang, Appl. Phys. Lett. 87, 375 (2000).

${ }^{15}$ T. Mori, H. Fujikawa, S. Tokito, and Y. Taga, Appl. Phys. Lett. 73, 2763 (1998).

${ }^{16}$ A. Schmidt, M. L. Anderson, and N. R. Armstrong, J. Appl. Phys. 78, 5619 (1995)

${ }^{17}$ K. Sugiyama, D. Yoshimura, T. Miyamae, T. Miyazaki, H. Ishii, Y. Ouchi, and K. Seki, J. Appl. Phys. 83, 4928 (1998).

${ }^{18}$ T. W. Pi, T. C. Yu, C. P. Ouyang, J. F. Wen, and H. L. Hsu, Phys. Rev. B 71, 205310 (2005).

${ }^{19}$ C. I. Wu and A. Kahn, Appl. Phys. Lett. 74, 1433 (1999).

${ }^{20}$ C. I. Wu and A. Kahn, J. Appl. Phys. 86, 3029 (1999).

${ }^{21}$ I. G. Hill, A. Kahn, J. Cornil, D. A. dos Santos, and J. L. Bredas, Chem. Phys. Lett. 317, 444 (2000).

${ }^{22}$ C. I. Wu, Y. Hirose, H. Sirringhaus, and A. Kahn, Chem. Phys. Lett. 272 43 (1997). 